\title{
Cardiac Echocardiography in COVID-19 Infection
}

\author{
Rohan Kapur $^{1}$ Naveen Garg ${ }^{2} \quad$ K. K. Kapur ${ }^{3}$ Pranav Kapoor ${ }^{4}$ Poonam Malhotra Kapoor ${ }^{5}$ \\ ${ }^{1}$ Non-Invasive Cardiac Lab, Indraprastha Apollo Hospital, \\ New Delhi, India \\ ${ }^{2}$ Non-invasive Lab Civil Hospital, Faridabad, Haryana, India \\ ${ }^{3}$ Non-Invasive Lab, Indraprastha Apollo Hospital, New Delhi, India \\ ${ }^{4}$ Internee, Sharda University, Noida, Uttar Pradesh, India \\ ${ }^{5}$ Department of Cardiac Anaesthesia, CTC, All India Institute of \\ Medical Sciences, New Delhi, India

\begin{abstract}
Address for correspondence K. K. Kapur, MBBS, MD(Medicine), DM(Cardiology), Non-Invasive Lab, Indraprastha Apollo Hospital, New Delhi,
\end{abstract} \\ India (e-mail: heartclinicnoida@gmail.com). \\ J Card Crit Care:2020;4:56-60
}

\begin{abstract}
Keywords

- cardiac involvement

- COVID infection

- echocardiography for cardiac evaluation

The novel COVID-19 disease mainly affects respiratory organs; however, involvement of cardiovascular system is also not uncommon. Cardiac involvement can manifest as myocarditis, heart failure, myocardial infarction, pulmonary embolism, or arrhythmias in COVID-19 patients. This novel Coronavirus enters into the cells of the human body by binding to ACE- 2 receptors which are predominantly present on pneumocytes and cardiomyocytes. The damage to myocardium is manifested by the increase in cardiac enzymes such as troponin-I, CK-MB, and NT pro-BNP. Although echocardiogram is an important tool in the cardiac evaluation of COVID-19 patients, its indiscriminate use is discouraged, owing to the risk of transmission to echocardiography service providers, as well as possible risk of contaminating echocardiography equipment. In this article, we discuss the different mechanisms and cardiac manifestations of COVID-19. We also review the current guidelines for echocardiography evaluation of COVID-19 patients as well as current recommendations on safety of echocardiography personnel and equipment against contamination. We also include our experience of two cases in which COVID-19 affliction of heart was strongly suspected, and echocardiography clinched the diagnosis.
\end{abstract}

\section{Introduction}

The Coronavirus pandemic, which started in late 2019 and is still ongoing, has severely stretched and overwhelmed the healthcare infrastructure all over the world. The SARS CoV-2 is transmitted by droplets, which enter the mucous membranes of the patients' eyes, nose, and mouth. ACE-2 receptors, predominantly present in the lungs, facilitate the entry of the virus into the cells. ${ }^{1}$

Cardiac involvement in the coronavirus infection is relatively uncommon in low-risk, younger, asymptomatic patients ( $<40$ yrs). In middle age/elderly patients, the cardiac involvement progressively increases, and in patients requiring intensive care facilities, with or without ventilator therapy, the prevalence of heart involvement rises steeply and could be in the range of 50 to $60 \% .^{1-4}$

\section{Cardiac Involvement due to Coronavirus Infection can Occur in (-Table 1$)$ :}

1) Patients with preexisting heart disease-coronary artery disease, well-compensated congenital heart disease, valvular heart disease, as well as those in whom there is involvement of the heart in comorbid conditions such as hypertension, diabetes and chronic kidney disease. These patients can undergo worsening and decompensation due to acute stress.

2) Direct/indirect involvement of myocardium (myocarditis) is as follows:

- Direct involvement of the myocardium occurs because of the viral RNA affecting the endothelium of the myocardial vessels, leading to release of troponins (troponin-T and I), causing varying degrees of myocardial dysfunction.
DOI https://doi.org/

10.1055/s-0040-1714150

ISSN 2457-0206.
License terms

(ㅇ) (1) $\Theta \circledast$ 
- Indirect involvement of the myocardium can occur as a result of a severe systemic inflammation, causing release of cytokines/chemokines. These proinflammatory cytokines like tumor necrosis factor (TNF), interleukin (IL)-6, ferritin, C-reactive protein (CRP), and IL-1 $\beta$ are overproduced in response to tissue injury. This phenomenon is called cytokine storm which leads to vascular hyperpermeability, plaque ruptures, and eventually multiorgan failure. This is mediated by activation of monocytes and macrophages.

- The presence of myocardial injury is an independent risk factor associated with increased mortality in COVID patients. ${ }^{5-8}$

3) Rupture of atherosclerotic plaque on a preexisting critical/noncritical coronary artery disease, causing acute myocardial infarction (MI), usually ST elevated myocardial infarction (STEMI).

- The management of patients with MI could either be using thrombolytic therapy (provided no C/I exist) or be directly referred to a percutaneous coronary intervention (PCI) center. The thrombolytic therapy regimen has the advantage of being cost-effective, immediately available, and more importantly avoiding transmission of infections to the interventional team. However, the advantage of PCI approach avoids unnecessary delays arising from changes in the appearance of classical findings of ECG in STEMI. ${ }^{5-8}$

4) Myocardial ischemia precipitated by myocardial supply/demand mismatch due to tachycardia, hypoxia, pyrexia, and systemic inflammation which could lead to severe left ventricle (LV) dysfunction. ${ }^{9,10}$

5) Cardiac arrhythmias varying from benign atrial/ventricular ectopics to life-threatening ventricular arrhythmias like Torsades de pointes, which could occur as a result of the following:

Myocardial inflammation; use of cardiotoxic medications like chloroquine, hydroxychloroquine, azithromycin antiviral drugs; congenital disorders such as Brugada syndrome and long QT; electrolyte imbalance ${ }^{11,12}$ (-Table 2).

6) Involvement of pericardium, including myopericarditis, and large pericardial effusions like cardiac tamponade are less frequent manifestations of COVID involvement of the heart.

7) Stress cardiomyopathy is again an uncommon reflection of COVID involvement of the heart, leading to either a classical Tako-Tsubo cardiomyopathy, a more rarer, reverse Tako-Tsubo cardiomyopathy, and nonischemic cardiomyopathy. ${ }^{13,14}$

8) Cardiac involvement due to pulmonary embolism.

- Acute vascular thrombosis including deep vein thrombosis (DVT) is more likely to occur in patients with severe COVID infection.

- Pulmonary embolism has a greater propensity to occur in patients with COVID pneumonias than other viral infections like influenza.
- The prevalence of pulmonary embolism is likely to be in the range of 20 to $30 \%$ in patients with COVID pneumonias.

- Significant elevation of D-dimer levels is likely to indicate a high-probability acute pulmonary embolism in a patient with COVID pneumonia and hypoxemia.

- Acute cor pulmonale causing right ventricular (RV) enlargement can occur as a result of pulmonary embolization or severe hypoxemia due to COVID pneumonia

Table 1 Cardiac involvement COVID-19

\begin{tabular}{|l|l|l|}
\hline Myocarditis & $\begin{array}{l}\text { Stress } \\
\text { cardiomyopathy }\end{array}$ & Arrythmias \\
\hline Heart failure & $\begin{array}{l}\text { Myocardial } \\
\text { infarction }\end{array}$ & Septic shock \\
\hline Pulmonary embolism & $\begin{array}{l}\text { Myocardial } \\
\text { ischemia due to } \\
\text { demand-supply } \\
\text { mismatch }\end{array}$ & $\begin{array}{l}\text { Cytokine storm } \\
\text { /multiorgan } \\
\text { failure }\end{array}$ \\
\hline
\end{tabular}

Table 2 Drugs linked to arrhythmias in COVID-19 patients

\begin{tabular}{|l|l|}
\hline Type of arrhythmia & Cautious use of drugs \\
\hline $\begin{array}{l}\text { Benign atrial/ventricular } \\
\text { ectopics }\end{array}$ & - \\
\hline $\begin{array}{l}\text { Congenital arrythmias: long } \\
\text { QT interval, short QT interval, } \\
\text { Brugada syndrome }\end{array}$ & $\begin{array}{l}\text { Chloroquine } \\
\text { Hydroxychloroquine } \\
\text { Azithromycin } \\
\text { Lopinavir/ritonavir }\end{array}$ \\
\hline $\begin{array}{l}\text { Catecholaminergic polymor- } \\
\text { phic ventricular tachycardia }\end{array}$ & $\begin{array}{l}\text { Epinephrine, dopamine and } \\
\text { dobutamine }\end{array}$ \\
\hline
\end{tabular}

itself. $^{15,16}$

- Recognition of pulmonary embolism is crucial to the management of such critically ill patients, as appropriate use of unfractionated heparin/low-molecular weight heparin could indeed be life-saving.

\section{Management}

The management of cardiac involvement during COVID infection could be challenging, especially with regard to treatment of hypotension, shock, decompensated cardiac failure, malignant arrhythmia, and electrolyte imbalance. Continuous ECG monitoring in the ICU/telemetric monitoring is an essential component for detecting/managing cardiac arrythmias. Various cardiac imaging modalities may be required, for example, echocardiography, cardiac CT, and MRI. Critical cardiac care also includes the use of inotropes, vasopressors, antiarrythmics, diuretics, as well as appropriate management of dyselectrolytemia. Many drugs are presently under trial for specific treatment of COVID-19 ( - Table 3).

\section{Use of Cardiac Imaging in the Management of COVID Patients: Guidelines and Protocols}

Echocardiography is the most widely used cardiac imaging modality as it is noninvasive, portable and extremely cost-effective with accurate and immediate results. However, the use of echocardiographic technique exposes 
Table 3 Anti-COVID drugs under investigation ${ }^{17-21}$

\begin{tabular}{|l|l|l|}
\hline Drugs & Mechanism of action & Comments \\
\hline Chloroquine/hydroxychloroquine & $\begin{array}{l}\text { inhibits the production and release of TNF } \\
\text { and IL-6 }\end{array}$ & No authoritative RCT \\
\hline Azithromycin & $\begin{array}{l}\text { Antibacterial with antiviral action- Inhibits } \\
\text { protein synthesis }\end{array}$ & No authoritative RCT \\
\hline Ritonavir/lopinavir & $\begin{array}{l}\text { Anti-HIV drugs-protease inhibitors } \\
\text { synthesis and replication }\end{array}$ & No authoritative RCT \\
\hline Remdesivir & Antibody to the IL-6 receptor & $\begin{array}{l}\text { Highly promising drug with randomized } \\
\text { study, showing significant reduction in } \\
\text { duration of active disease among severely } \\
\text { ill patients. }\end{array}$ \\
\hline Tocilizumab & $\begin{array}{l}\text { Antihelminthic drug which reduces } \\
\text { COVID-19 replication in vitro }\end{array}$ & Used for cytokine storm \\
\hline Ivermectin & Antibodies in plasma of recovered patients & Promising therapy undergoing trials \\
\hline Plasma therapy & \\
\hline
\end{tabular}

Abbreviation: RCT, randomized control trial.

the operator to a high-risk of being infected by the COVID patients; also, there is risk of contamination of the echocardiographic equipment in the COVID ICU (- Table 4).

- Echocardiographic procedure should only be used if there is likelihood of being incremental advantage in the management of the COVID patient with suspected/ diagnosed cardiac involvement. Furthermore, echocardiography should be used if it is likely to provide substantial change in management strategy (drug therapy, interventional therapy, or cardiac surgery). Thus, the use of echocardiography should be restricted to the following situations:

1) Hemodynamically unstable patients.

2) Patient with decompensated cardiac failure.

3) Heart murmur.

4) Evaluation of patients with known preexisting cardiac disease. ${ }^{21,22}$

- However elaborate precautions should be undertaken with regard to protection of the personnel with adequate personal protection equipment (PPE) as well as protection of echocardiographic equipment from contamination. The detailed process of protection of the equipment can be divided into:

\section{A) Before the echocardiographic procedure:}

1) Echocardiographic machine is carefully and thoroughly cleaned with sodium hypochlorite solution, including transducers, knobs, touch screen panel, and the monitor of the machine.

2) After drying, the knobs' board, touch screen panel, monitor, and transducer, are then completely covered with transparent polythene, as shown in - Fig. 1.

3) The main body of the echocardiography machine, the transducer connecting cords, connectors, as well as the electrical wires, are draped in an outer polythene covering, as shown in - Fig. 1.
Table 4 Appropriate use criteria for echocardiograph ${ }^{22,23}$

\begin{tabular}{|c|}
\hline $\begin{array}{l}\text { Only POCUS or FOCUS views are recommended for quick assess } \\
\text { ment in critical areas }\end{array}$ \\
\hline Measurements for LV, RV and LA can be performed offline. \\
\hline TTE (off axis views or contrast) preferred over TEE \\
\hline Use of CT or MRI instead of TEE preferred in cases like LAA clot \\
\hline $\begin{array}{l}\text { Pharmacological stress tests may be preferred over treadmill } \\
\text { stress }\end{array}$ \\
\hline
\end{tabular}

Abbreviations: LA, left atrial; LAA, left atrial appendage; LV, left ventricle; TEE, transesophageal echocardiography; TTE, transthoracic echocardiography; RA, right atrial; RV, right ventricle.

B) During echocardiographic procedure on a COVID patient, the outer draping of the body is removed, while the transducers, touch panel, monitor and knobs remain covered with transparent polythene.

C) After the echocardiographic procedure, the echo machine is wheeled back to the echo room, and all the polythene coverings are removed. The entire echocardiographic machine is again cleaned meticulously with sodium hypochlorite solution, and the entire process is then repeated for another examination on COVID/suspected COVID patient.

- High-quality PPE should be provided (as shown in -Fig. 1), including complete covering of the face, eye-protection glasses, and headgear.

- ECG leads need not be attached to the echocardiographic equipment. The examination should consist of four or five basic views (parasternal LA/SA, Apical 4C/2C, and subcostal or hypochondrial views). The basic aim of the imaging should be:

1. To provide assessment of the LV size and function.

2. To provide assessment of the RV size and function.

3. Rapid nondetailed assessment of cardiac valves.

4. Assessment of pericardial/pleural effusion.

5. Assessment of fluid status (central venous pressure by inferior vena cava [IVC] size). 


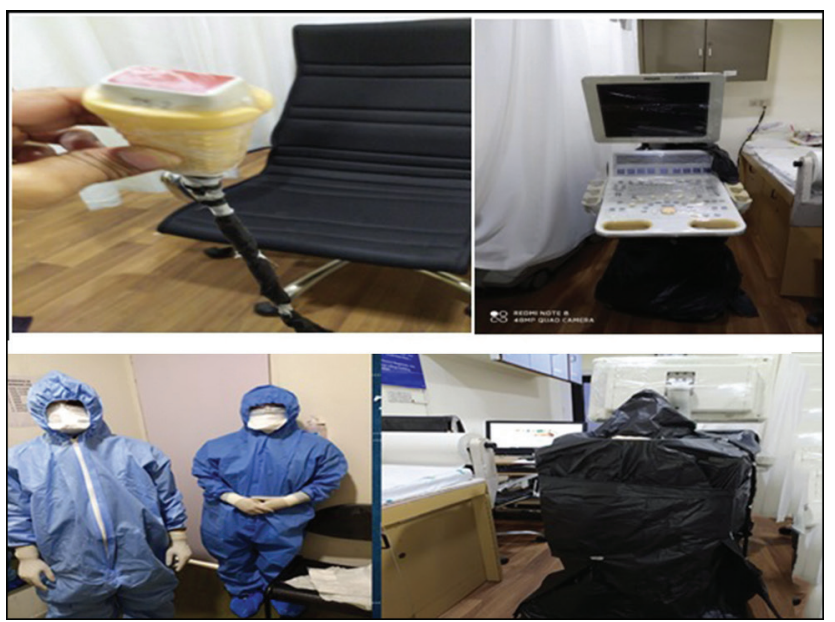

Fig. 1 Depicting use of PPE by echocardiography providers, and safety measures for echo equipment.

6. A Doppler assessment of the mitral inflow and LV outflow is usually sufficient to provide the required hemodynamics - Table 5.

- Echocardiographic personnel have a high-probability of getting infected when a transesophageal (TEE) procedure is performed on a COVID patient. Therefore, as far as possible, TEE should be avoided. One of the most common indication is to detect LA appendage clot in patients with atrial fibrillation (AF), or those having a history of embolic stroke. The use of MRI/CT could be extremely useful in this respect, owing to a much lesser probability of transmission of the virus to the MRI/CT personnel, as they are at a considerable distance from the patient. However, protection of the CT/MRI equipment from contamination is extremely important and due diligence should be followed.

- Echocardiographic procedure could be obviated if:

1) Troponin and NT pro-BNP levels are normal

2) If an LV angiogram is performed during PCI in a COVID patient with MI.

3) Similarly, if CT angiogram is done for suspected pulmonary embolism, CT angiographic imaging of the heart and the coronaries can provide adequate information and prevent unnecessary echocardiographic procedure.

- If patient is critically ill and CT angiography cannot be performed, then echocardiography could be performed to make a direct/indirect diagnosis of a probable pulmonary embolism (occasionally direct imaging of pulmonary artery [PA] clot but more commonly RV dysfunction and low-flow states in PA).

\section{Authors' Experience with COVID-19 (Case-Studies)}

CASE 1-A 61-year-old hypertensive male with no previous history of chronic obstructive (COPD) and diabetes; COVID-19 positive with pulmonary pneumonia was under treatment in ICU. His heart rate (HR)-120/min, blood pressure (BP)-100/60 mm Hg, respiratory rate (RR) 32/min, and SPO2 92\% at room air (-Fig. 2 a, b).
Table 5 FOCUS echocardiographic evaluation of COVID-19 patients

\begin{tabular}{|l|l|l|}
\hline $\begin{array}{l}\text { Pericardial } \\
\text { effusion }\end{array}$ & $\begin{array}{l}\text { Pulmonary } \\
\text { embolism }\end{array}$ & $\begin{array}{l}\text { Gross valvular stenosis/ } \\
\text { regurgitation }\end{array}$ \\
\hline $\begin{array}{l}\text { LV systolic } \\
\text { dysfunction }\end{array}$ & $\begin{array}{l}\text { RV } \\
\text { dysfunction }\end{array}$ & $\begin{array}{l}\text { Regional wall motion } \\
\text { abnormality }\end{array}$ \\
\hline $\begin{array}{l}\text { IVC for fluid } \\
\text { status }\end{array}$ & $\begin{array}{l}\text { Vascular scan } \\
\text { for DVT }\end{array}$ & \\
\hline
\end{tabular}

Abbreviations: IVC, inferior vena cava; DVT, deep vein thrombosis; LV, left ventricle; RV, right ventricle.

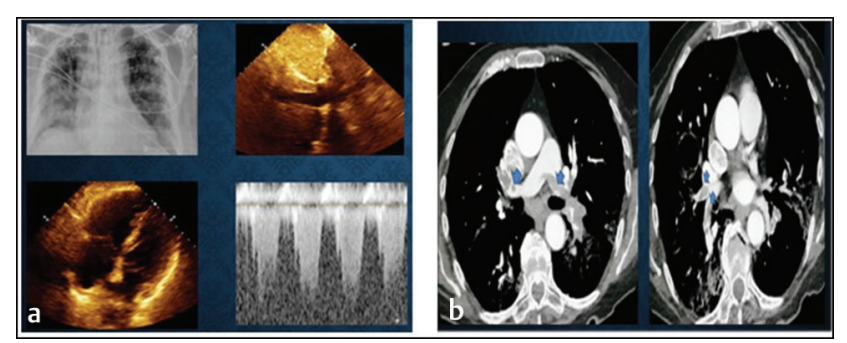

Fig. 2 (a) and (b) Chest X-ray depicting bilateral interstitial infiltrates. Rapid echocardiogram showed dilated RV and IVC, and TR jet PASP $>40 \mathrm{~mm} \mathrm{Hg}$. Diagnosis of acute pulmonary embolism was made, which was confirmed with CT scan as (a) revealed ground glass opacities and pulmonary thrombi bilateral (blue arrows), detected up to segmental branches. Abbreviations: IVC, inferior vena cava; PASP, pulmonary artery systolic pressure; RV, right ventricle.

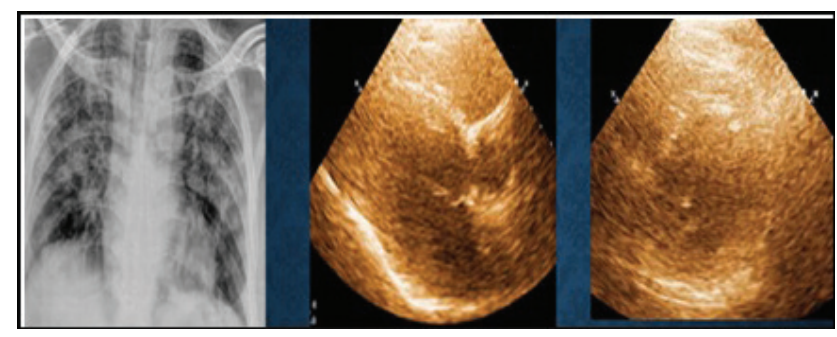

Fig. 3 Chest $X$-ray revealed $B / L$ consolidation. Echocardiography revealed normal LV function. Abbreviation: LV, left ventricle.

Case 2-A 65-year-old diabetic male, with h/o high fever along with breathing difficulty, was admitted with hemodynamic instability for further management. X-Ray revealed large B/L consolidation. His HR-120/min, BP-80/60 mm Hg, and SPO2-88\% at room air. Emergency echocardiography was done with a strong suspicion of myocarditis ( - Fig. 3 ).

Hematological investigations revealed leucocytosis and lymphopenia. COVID test was positive. Echocardiography ruled out any direct or indirect involvement of heart in this patient. Later troponin and NT-proBNP levels were also found to be normal.

\section{Conclusion}

Although COVID involvement of the heart is uncommon in young, asymptomatic individuals; it is likely to be a challenging situation in the middle age/elderly population, especially with comorbid conditions. Appropriate management of decompensated, unstable, cardiac 
patients in the COVID ICU is extremely demanding and requires expert management. A judicious use of echocardiography is advised. Hemodynamically, unstable patients may require echocardiography, but in patients with normal troponin levels, its use may be obviated. For performing an additional LV angiogram in patients undergoing coronary angiography or cardiac evaluation by CT scan in patients undergoing CT of the chest for pulmonary embolism, the need of echocardiography can be deferred. However, where patients cannot be transported, bedside echocardiography is an important tool. Provision of high-quality PPE, disinfecting, and draping of the echocardiographic equipment is essential. In the two patients described above, the use of echocardiography was crucial to diagnosis.

\section{Conflict of Interest}

None.

\section{References}

1 Guzik TJ, Mohiddin SA, Dimarco A, et al. COVID-19 and the cardiovascular system: implications for risk assessment, diagnosis, and treatment options. Cardiovasc Res 2020;:cvaa106

2 Kuster GM, Pfister O, Burkard T, et al. SARS-CoV2: should inhibitors of the renin-angiotensin system be withdrawn in patients with COVID-19? Eur Heart J 2020;41(19):1801-1803

3 Basu-Ray I, Soos MP, Cardiac Manifestations of Coronavirus (COVID-19) A service of the National Library of Medicine, National Institutes of Health; 2020

4 Zheng YY, Ma YT, Zhang JY, Xie X. COVID-19 and the cardiovascular system. Nat Rev Cardiol 2020;17(5):259-260

5 Mahmud E, Dauerman HL, Welt FG, et al. Management of acute myocardial infarction during the COVID-19 pandemic. J Am Coll Cardiol 2020;S0735-1097(20)35026-35029

6 Mahmud E, Dauerman HL, Welt FGP, et al. Management of acute myocardial infarction during the COVID-19 pandemic: A Consensus Statement from the Society for Cardiovascular Angiography and Interventions (SCAI), the American College of Cardiology (ACC), and the American College of Emergency Physicians (ACEP). Catheter Cardiovasc Interv 2020. Doi: 10.1002/ccd.28946. doi:10.1002/ccd.28946

7 Kwong JC, Schwartz KL, Campitelli MA, et al. Acute myocardial infarction after laboratory-confirmed influenza infection. $\mathrm{N}$ Engl J Med 2018;378(4):345-353

8 Smeeth L, Thomas SL, Hall AJ, Hubbard R, Farrington P, Vallance P. Risk of myocardial infarction and stroke after acute infection or vaccination. N Engl J Med 2004;351(25):2611-2618

9 Shi S, Qin M, Shen B, et al. Association of cardiac injury with mortality in hospitalized patients with COVID-19 in Wuhan, China. JAMA Cardiol 2020;(e-pub ahead of print). doi: 10.1001/jamacardio.2020.0950

10 Guo T, Fan Y, Chen M, et al. Cardiovascular implications of fatal outcomes of patients with coronavirus disease 2019
(COVID-19) JAMA Cardiol 2020;(e-pub ahead of print). doi: 10.1001/jamacardio.2020.1017

11 Prutkin JM, Knight BP, et al. Coronavirus Disease (COVID-19): Arrhythmias and Conduction System Disease. Available at: https://www.uptodate.com/contents/coronavirus-disease-2019. Accessed May 24, 2020

12 Lakkireddy DR, Chung MK, Gopinathannair R, et al; Guidance for Cardiac Electrophysiology During the Coronavirus (COVID-19) Pandemic from the Heart Rhythm Society COVID-19 Task Force. Guidance for Cardiac Electrophysiology During the Coronavirus (COVID-19) Pandemic from the Heart Rhythm Society COVID-19 Task Force; Electrophysiology Section of the American College of Cardiology; and the Electrocardiography and Arrhythmias Committee of the Council on Clinical Cardiology, American Heart Association. Circulation 2020;(e-pub ahead of print). doi:10.1161/ CIRCULATIONAHA.120.047063

13 Ezad S, McGee M, Boyle AJ. Takotsubo syndrome associated with ST elevation myocardial infarction. Case Rep Cardiol 2019;2019:1010243

14 Roca E, Lombardi C, et al. Takotsubo Syndrome Associated with COVID-19. Available at: https://www.ejcrim.com/index.php/ EJCRIM/article/view/1665/2065. Accessed May 24, 2020

15 Tang N, Li D, Wang X, Sun Z. Abnormal coagulation parameters are associated with poor prognosis in patients with novel coronavirus pneumonia. J Thromb Haemost 2020;18(4):844-847

16 Danzi GB, Loffi M, Galeazzi G, Gherbesi E. Acute pulmonary embolism and COVID-19 pneumonia: a random association? Eur Heart J 2020;41(19):1858

17 Wang Y, Zhang D, Du G, et al. Remdesivir in adults with severe COVID-19: a randomised, double-blind, placebo-controlled, multicentre trial. Lancet 2020;395(10236):1569-1578

18 Nakkazi E. Randomised controlled trial begins for Ebola therapeutics. Lancet 2018;392(10162):2338

19 Liu J, Cao R, Xu M, et al. Hydroxychloroquine, a less toxic derivative of chloroquine, is effective in inhibiting SARS-CoV-2 infection in vitro. Cell Discov 2020;6:16

20 Maisch B, Alter P. Treatment options in myocarditis and inflammatory cardiomyopathy: focus on i. v. immunoglobulins. Herz 2018;43(5):423-430

21 Chatre C, Roubille F, Vernhet H, Jorgensen C, Pers YM. Cardiac complications attributed to chloroquine and hydroxychloroquine: a systematic review of the literature. Drug Saf 2018;41(10):919-931

22 Kirkpatrick J, Mitchell C, Taub C, et al. ASE Statement on Protection of Patients and Echocardiography Service Providers During the 2019 Novel Coronavirus Outbreak. Available at: https://www.asecho.org/wp-content/uploads/2020/03/ COVIDStatementFINAL4-1-2020_v2_website.pdf. Accessed April 13, 2020

23 Peng Q-Y, Wang X-T, Zhang LN; Chinese Critical Care Ultrasound Study Group (CCUSG). Using echocardiography to guide the treatment of novel coronavirus pneumonia. Crit Care 2020;24(1):143 